\title{
FREQUENCY OF DEPRESSION IN PATIENTS WITH RHEUMATOID ARTHRITIS.
}

1. MBBS, FCPS (Psychiatry) Assistant Professor Psychiatry Nishtar Medical University, Multan.

2. MBBS, FCPS (Psychiatry)

Assistant Professor \& Chairperson Psychiatry

Ghazi Khan Medical College, Dera Ghazi Khan.

3. MBBS,

FCPS (Community Medicine)

Demonstrator Community Medicine Multan Medical \& Dental College,

Multan.

4. MBBS

Student $4^{\text {th }}$ Year

CMH Lahore Medical College, Lahore.

Correspondence Address:

Dr. Owais Kareem

Assistant Professor Psychiatry

Nishtar Medical University, Multan.

owaiskareem@hotmail.com

Article received on:

14/10/2019

Accepted for publication

05/01/2020
Owais Kareem ${ }^{1}$, Hafiz Shafique Ahmad ${ }^{2}$, Bushra ljaz ${ }^{3}$, Shiza Altaf ${ }^{4}$

ABSTRACT: Co morbid depression in rheumatoid arthritis is associated with higher levels of disease activity, pain, fatigue, work disability, health service use and lower treatment compliance. Objectives: To determine the frequency of depression among patients with rheumatoid arthritis. Study Design: Cross sectional, descriptive study. Setting: Pain clinic, Outpatient department, Nishtar Hospital, Multan. Period: Eight months from 10-11-2015 to 1006-2016. Material \& Methods: The total 174 patients with rheumatoid arthritis were enrolled through the non-probability consecutive sampling technique. Results pertaining to rates were reported as frequencies and percentages. Pearson chi squared test was applied to identify the significant associations between study variables. Results: Among the total 174; (100\%) study participants, depression was noted in 116; $(66.7 \%)$ of participants. Forty-three (24.7\%) of study participants were males and 131; $(75.3 \%)$ were females. Calculated mean age of participants was $48.47 \pm 8.09$ years. Statistically significant associations of depression were noted with duration, treatment and symptom of rheumatoid arthritis. Conclusion: A high frequency of the depression was noted among patients with rheumatoid arthritis, which was associated with poor outcomes of rheumatoid arthritis. This suggests that the optimal care of rheumatoid arthritis should include detection and management of depression.

Key words: $\quad$ Depression, Multan, Nishtar Hospital, Pakistan, Rheumatoid Arthritis.

Article Citation: Kareem O, Ahmad HS, ljaz B, Altaf S. Frequency of depression in patients with rheumatoid arthritis. Professional Med J 2020; $27(3): 646-650$. DOI: 10.29309/TPMJ/2020.27.3.4242

\section{INTRODUCTION}

The global burden of disease 2016 study indicated that depressive disorder accounts for the third largest share of the world's burden of disease in terms of years lost to disability. ${ }^{1}$

The prevalence of depression is $17 \%$ to $53 \%{ }^{2}$ in people with a medical condition that is much higher than its prevalence in the general population that is $10 \%$ to $20 \%{ }^{3}$

Like depression, rheumatoid arthritis is also a major contributor to global disability. ${ }^{1}$ Rheumatoid arthritis is the most common persistent inflammatory arthritis occurs throughout the world. It usually follows a long course, which is often complicated with multiple exacerbations and remissions. ${ }^{4}$

Depression and rheumatoid arthritis often coexist which underlines the potential role of inflammatory processes as a predisposition for both conditions. ${ }^{5}$

Research also indicated a bidirectional link may exist between rheumatoid arthritis and depression with each disorder predicting an increased subsequent risk for the other. ${ }^{6}$ Prevalence of rheumatoid arthritis in the world is $0.5-1 \%{ }^{7}$

In Pakistan the prevalence of rheumatoid arthritis falls between 0.9 to $1.98 \% .^{8}$ Several studies have reported the prevalence of depression in patients of rheumatoid arthritis. Dickens et al reported the prevalence as $13 \% .{ }^{9}$ Whereas another study estimated the prevalence between $14.8 \%$ to $34.2 \% .10$

In Pakistan, the frequency of depression in patients of rheumatoid arthritis was reported as $56.5 \%{ }^{11}$ while another study reported the prevalence of depression in rheumatoid arthritis 
as $65.8 \% .^{12}$

Published literature has indicated clearer benefits of treating depression in patients who had a co morbid physical condition. ${ }^{13}$ Furthermore untreated depression in rheumatoid arthritis is associated with higher levels of disease activity, pain, fatigue, work disability, health service use, lower treatment compliance, increased suicide risk and mortality. ${ }^{14}$

A wide variability in frequency of depression in rheumatoid arthritis has been reported. Even studies in Pakistan showed the prevalence rate as $56.5 \%{ }^{11}$ and $65.8 \%{ }^{12}$ respectively. Despite the widely accepted fact that co-occurrence of these two disorders can lead to poor effective treatment, no study has been conducted in South Punjab to note the frequency of depression in rheumatoid arthritis.

Therefore, we aimed to determine the frequency of depression in rheumatoid arthritis in our locality. Our results will improve awareness, early identification and thus treatment of depression in rheumatoid arthritis may be initiated which are critical to overall clinical management. ${ }^{15}$

\section{MATERIAL AND METHODS}

After approval, the descriptive cross sectional study was conducted at Pain Clinic, Out Patient Department, Nishtar Hospital, Multan, Pakistan from 10-11-2015 to 10-06-2016. By taking 95\% as confidence interval, $5 \%$ error of margin, $z$ value of 1.96 and $p$ value of 13 the sample size of 174 was calculated by the formula $\left(n=z^{2} p q / d^{2}\right) \cdot{ }^{11}$ Non probability consecutive sampling technique was used to collect the sample. Informed consent and confidentiality were ensured for every participant. Patients of either sex, aged 35 - 65 years, having rheumatoid arthritis who scores 6 or $>6$ according to the 2010 ACR / EULAR Rheumatoid Arthritis Classification Criteria for Rheumatoid Arthritis were included. ${ }^{16}$

Patients with history of depression prior to the diagnosis of rheumatoid arthritis, pregnant females and patients with history of any other medical disorders were excluded. For screening depression among included participants, a validated Urdu version of Hospital Anxiety and Depression Scale (HADS-D) a 7-item scale was employed. Each item in the scale can be scored between 0-3.

The scores of 8 or $>8$ detects presence of depression without categorizing depression into mild, moderate, severe or stupor type. ${ }^{17}$ Data was entered and analyzed with SPSS version 19. Presence of depression was taken as a dependent variable whereas age, gender, disease duration, treatment status, duration of treatment and symptom control were taken as independent variables. Descriptive statistics of variables were reported as frequencies and percentages. Post stratification Pearson chi square test was applied to explore the significance of associations between dependent and independent variables. $P$ value equal to or less than 0.05 was considered as significant.

\section{RESULTS}

Among the total 174; (100\%) study participants, depression was noted in 116 (66.7\%) of participants. Forty-three (24.7\%) of study participants were males while 131; (75.3\%) were females. Mean age of our study cases was 48.47 \pm 8.09 years (with minimum age was 38 years while maximum age was 62 years). Mean duration of disease (rheumatoid arthritis) was $30.59 \pm 9.81$ months (with minimum disease duration was 18 months while maximum disease duration was 48 months).

Our study results have indicated that majority of patients 92 ; (52.9\%) had disease duration of more than 30 months. One hundred and one $(58 \%)$ were taking treatment for the rheumatoid arthritis. Forty-three patients $(24.7 \%)$ were on treatment for less than 1 year, 43 (24.7\%) were taking treatment for $1-2$ years while only 15 (8.6\%) were taking treatment for more than 2 years. Symptoms of rheumatoid arthritis were controlled in $58(33.3 \%)$ of our study cases. Statistical significant association of depression was noted with duration, treatment and symptoms control of rheumatoid arthritis Table-I. 


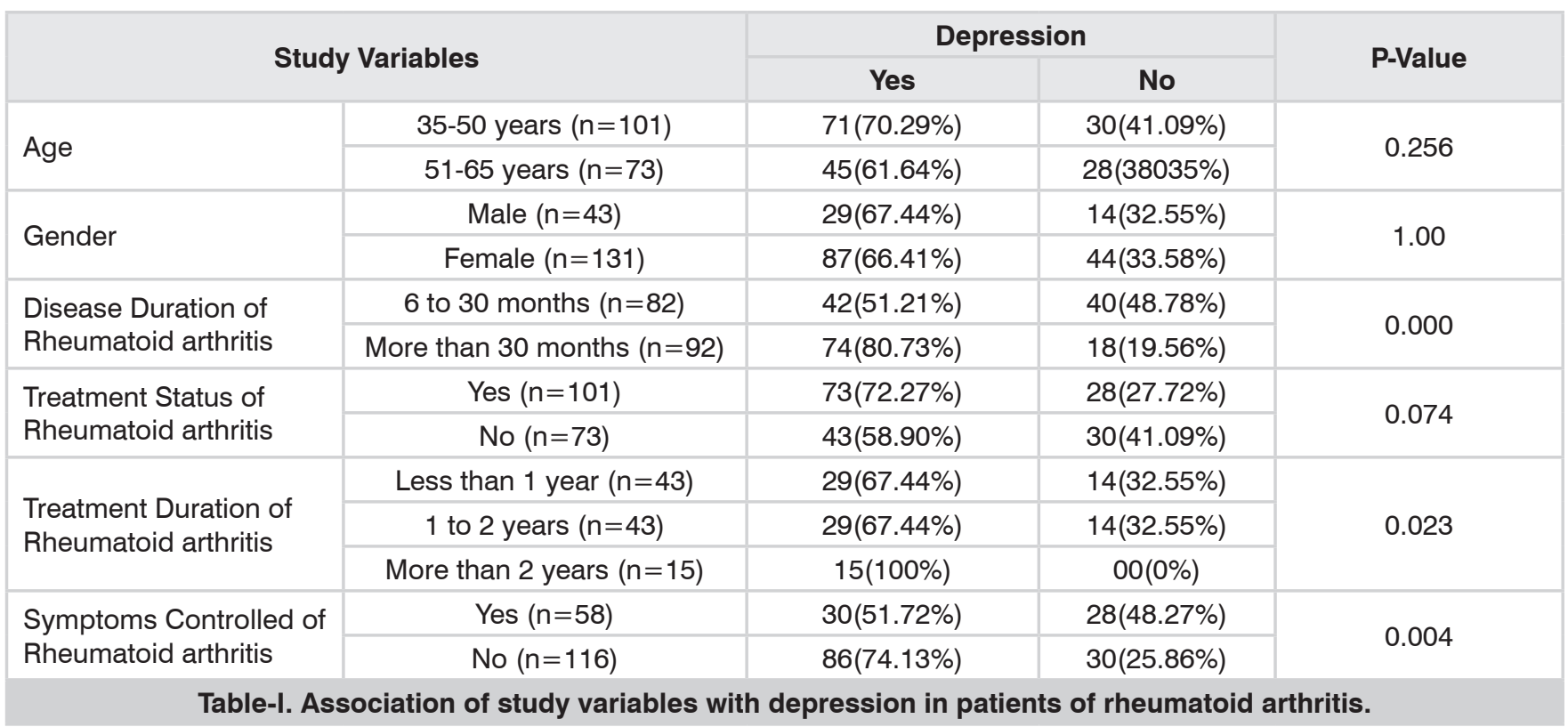

\section{DISCUSSION}

Our study revealed that the prevalence of depression in patients of rheumatoid arthritis was $66.7 \%$. Our estimated rate was close to the rate reported in a study conducted in Rawalpindi, which reported $56.5 \%{ }^{11}$ and a study conducted in Karachi, which reported $65.3 \%{ }^{12}$ of patients with rheumatoid arthritis had depression. The high rate of depression reported in our study further highlighted a previous study that indeed a bidirectional link is present between rheumatoid arthritis and depression. ${ }^{5}$ Additionally our results supported the finding of a study conducted in Lahore $^{18}$ that among the included participants, majority $(75.3 \%)$ of females reported with rheumatoid arthritis and depression as compared to $(24.7 \%)$ males. Study conducted in Australia and Japan also showed female preponderance towards development of rheumatoid arthritis co morbid with depression. ${ }^{19,20}$

Our study has indicated that majority of our study participants $(58 \%)$ had their ages ranging from 35 to 50 years with the mean age of $48.47 \pm 8.09$. It corroborated with a previous study result which documented the mean age of the patients with rheumatoid arthritis as $43.5 \pm 11.9$ years. ${ }^{18}$ This result also supports the fact that the age of onset of rheumatoid arthritis is most frequent during the fourth and sixth decade of life. ${ }^{21}$
Additionally we found significant association of depression with duration, treatment and symptoms control of rheumatoid arthritis. Our study has demonstrated that majority of reported patients (52.9\%) had rheumatoid arthritis for the duration of more than 30 months with a mean duration of $30.59 \pm 9.81$ months. This result however disputes with another study, which did not establish an association between depression and duration of rheumatoid arthritis. ${ }^{12}$

Moreover, we have found that the participants who had continued treatment for rheumatoid arthritis over two years and the participants with the symptoms of rheumatoid arthritis under control had the lowest rates of depression. These findings collaborate with the recent data which indicated that significant reductions in depression is correlated with a decrease disease activity of rheumatoid arthritis.

\section{CONCLUSION}

A very high frequency of the depression among patients with rheumatoid arthritis was noted in our study, which was associated with poor outcomes of rheumatoid arthritis. Depression was significantly associated with prolonged disease duration, poor symptoms control and duration of treatment. This suggests that optimal care of rheumatoid arthritis may include detection 
and management of depression. The care may include a close liaison between rheumatology and psychiatry departments. Furthermore, a rheumatologist should identify symptoms of depression in their patients by careful observation and screening of depression by a valid scale combined with a detailed medical and social assessment. If further needed a timely referral to a psychiatrist is recommended.

Copyright@ 05 Jan, 2020.

\section{REFERENCES}

1. GBD 2016 Disease and injury incidence and prevalence collaborators. Global, regional, and national incidence, prevalence, and years lived with disability for 328 diseases and injuries for 195 countries, 1990-2016: A systematic analysis for the Global Burden of Disease Study 2016. Lancet 2017; 390: 1211-59.

2. Hairong N, Paul HL, lan MD, Michael YN, Sunita MS, Tai HL. Depressive symptoms in people with chronic physical conditions: Prevalence and risk factors in a Hong Kong community sample. BMC Psychiatry. 2012; 12:198-9.

3. Cowen P, Harrison P, Burns T. Psychiatry and medicine. In: Cowen P, Harrison P, Burns T, editors. Shorter oxford textbook of psychiatry. Oxford: Oxford University Press; 2012. p. 379-419.

4. Ralston SH, Mclnnes IB. Rheumatology and bone disease. In: Walker BR, Colledge NR, Ralston SL, Penman LD, editors. Davidson's principles and practice of medicine. Edinburgh: Churchill Livingstone; 2014. p. 1057-1135.

5. Nerurkar L, Siebert S, Mclnnes IB, Cavanagh J. Rheumatoid arthritis and depression: An inflammatory perspective. Lancet Psychiatry. 2019 Feb; 6(2):164-173. doi: 10.1016/S2215-0366(18)302554.

6. Lu MC, Guo HR, Lin MC, Livneh H, Lai NS, Tsai TY. Bidirectional associations between rheumatoid arthritis and depression: A nationwide longitudinal study. Sci Rep. 2016; 6:20647).

7. Covic T, Cumming SR, Pallant JF, Manolios N, Emery P, Conaghan PG, et al. Depression and anxiety in patients with rheumatoid arthritis: prevalence rates based on a comparison of the depression, anxiety and stress scale (DASS) and the hospital, anxiety and depression scale (HADS). BMC Psychiatry. 2012; 12:6-15.
8. Hameed K, Gibson T, Kadir M, Sultana S, Fatima Z, Syed $A$. The prevalence of rheumatoid arthritis in affluent and poor urban communities of Pakistan. $\mathrm{Br}$ J Rheumatol. 1995; 34:252-6.

9. Dickens C, McGowan L, Clark-Carter D, Creed F. Depression in rheumatoid arthritis: a systematic review of the literature with meta-analysis. Psychosom Med.2002; 64(1):52-60.

10. Matcham F, Rayner L, Steer S, Hotopf M. The prevalence of depression in rheumatoid arthritis: $A$ systematic review and meta-analysis. Rheumatology (Oxford). 2013; 52(12):2136-48.

11. Azad N, Gondal M, Abbass N. Frequency of depression and anxiety in patients attending a rheumatology clinic. J Coll Physicians Surg Pak. 2008; 18(9):569-73.

12. Waheed A, Kamran H, Khan AM, Syed JA, Mirza Al. The burden of anxiety and depression among patients with chronic rheumatologic disorders at a tertiary care hospital clinic in Karachi, Pakistan. J Pak Med Assoc. 2006; 56(5)243-7.

13. Cowen P, Harrison P, Burns T. Psychiatry and medicine. In: Cowen P, Harrison P, Burns T, editors. Shorter oxford textbook of psychiatry. Oxford: Oxford University Press; 2012. p. 379-419.

14. Covic T, Cumming SR, Pallant JF, Manolios N, Emery $P$, Conaghan PG, et al. Depression and anxiety in patients with rheumatoid arthritis: Prevalence rates based on a comparison of the depression, anxiety and stress scale (DASS) and the hospital, anxiety and depression scale (HADS). BMC Psychiatry. 2012; 12:6-15.

15. Abu Al-Fad EM, Ismail MA, Thabit M, El-Serogy Y. Assessment of health related quality of life, anxiety and depression in patients with early rheumatoid arthritis. Egypt Rheumatol. 2014; 36:51-6.

16. Aletaha D, Neogi T, Silman AJ, Funovits J, Felson DT, Bingham CO. 2010 rheumotoid arthritis classification criteria. Arthritis Rheum. 2010; 62(9):2569-81.

17. Mumford DB, Tareen IA, Bajwa MA, Bhatti MR, Karim $R$. The translation and evaluation of an urdu version of the hospital anxiety and depression scale. Acta PsychiatrScand 1991 Feb; 83(2):81-5.

18. Imran MY, Khan EAS, Ahmad NM, Raja SF, Saeed MA, Haider II. Depression in rheumatoid arthritis and its relation to disease activity. Pak J Med Sci. 2015; 31 (2): 393-7. 
19. Covic T, Tyson G, Spencer D, Howe G. Depression in rheumatoid arthritis patients: demographic, clinical, and psychological predictors. J Psychosom Res. 2006; 60(5):469-76.

20. Sato E, Nishimura K, Nakajima A, Okamoto H, Shinozaki $M$, Inoue $E$, Taniguchi $A$, et al. Major depressive disorder in patients with rheumatoid arthritis. Mod Rheumatol. 2013; 23(2):237-44.
21. Alam $S$ et al. Epidemiology of rheumatoid arthritis in a tertiary care unit, Karachi, Pakistan. J Pak Med Assoc. $2011 \mathrm{Feb}$; 61: (2):123-126.

\begin{tabular}{|c|l|l|c|}
\hline \multicolumn{3}{|c|}{ AUTHORSHIP AND CONTRIBUTION DECLARATION } \\
\hline Sr. \# & \multicolumn{1}{|c|}{ Author(s) Full Name } & \multicolumn{1}{|c|}{ Contribution to the paper } & Author(s) Signature \\
\hline 1 & Owais Kareem & $\begin{array}{l}\text { Literature search, Study concept, Study } \\
\text { design, Data collection, data interpretation, } \\
\text { drafting, revision for accountability. } \\
\text { Study design, questionnaire design, data } \\
\text { analysis. }\end{array}$ \\
\hline 2 & Hafiz Shafique Ahmad & $\begin{array}{l}\text { Study design, literature search, } \\
\text { questionnaire design. } \\
\text { Literature search data collection, drafting. }\end{array}$ \\
\hline 4 & Bushra ljaz & Shiza Altaf & Shiza. \\
\hline
\end{tabular}

